\title{
PAISAJES, GEOGRAFÍA LITERARIA E IDENTIDAD NACIONAL ${ }^{1}$
}

\author{
M. a Teresa Vilariño Picos \\ Universidade de Santiago de Compostela \\ "Dime el paisaje en que vives y te diré quien eres" \\ José Ortega y Gasset, "La pedagogía del paísaje" (1906)²
}

Si parafraseamos, para comenzar, las palabras de Mario J. Valdés y Linda Hutcheon en Rethinking Literary History Comparatively (1994: 3) podemos manifestar que el estudio de la literatura necesita ser enmarcado en los límites de lo que los dos autores denominan Historia de la cultura literaria comparada o historiografía comparada de la cultura literaria (Anderson, 1983). Dentro de esos límites, el fenómeno literario trasciende los niveles estéticos y formales, tomando en consideración otros campos que como el político, antropológico, económico, geográfico, histórico, demográfico y sociológico articulan los contextos de una comunidad literaria. Una de las ideas fundamentales que defiende esta historia comparada de las literaturas, cultural por añadidura, es aquella que se encamina a un replanteamiento del concepto de nación, artificial, en muchos casos, y frágil como las mismas fronteras nacionales; porque los "bordes", como entidades históricas que son, cambian constantemente, de modo que cualquier construcción monolítica de una historia literaria nacional corre el riesgo de marginar, $\mathrm{c}$ incluso excluir, creaciones culturales que surgen en la periferia (Valdés y Hutcheon, ibidem).

Las líneas de trabajo que quiero desglosar a continuación pretenden explicar, dentro de una teoría general del ensayo, de qué manera se ha desarrollado el imaginario cultural nacional en España y Portugal, como un sistema entre sucesivos sistemas de valores compartidos finiseculares, extendidos hacia las primeras décadas del siglo XX (Valdés, 1999: 212). Se trata de un "imaginario colectivo", una "continuidad", en términos azorinianos, a partir de la interpretación del paisaje verbal, expresión física de las obras humanas, geográfico y, sobre todo, cultural (cfr: C. Sauer, 1971).

1.- Este artículo ha sido concebido en el marco del proyecto de investigación dirigido por el Profesor Fernando Cabo Aseguinolaza, Historia Comparada de las literaturas: Aplicaciones al dominio ibérico (HUM2004-00314/FILO). 2.- En reconocimiento a la maestría y amistad de Mario Valdés, a quien debo tantas cosas. Y a María Eilena de Valdés. A los dos, todo mi cariño. 


\section{PAISAJES, GEOGRAFÍA LITERARIA E IDENTIDAD NACIONAL}

A pesar de esta continuidad aparente, es preciso hacer hincapié en que, tal y como ha revisado Javier Varela en La novela de España (1999), el desastre del 98 no incide de la misma manera en Portugal que en nuestro país. En el caso portugués, para encontrar rasgos de defensa de un pucblo, de una raza y de una etnia propia, acompañados por la crisis nacional, transmitidos por la literatura, y por el paisaje, habría que analizar a Eça de Queirós, en primer lugar, para continuar con el neogarretismo y finalizar en el saudosismo de Teixeira de Pascoaes ${ }^{3}$.

De otro lado, La España finisecular queda muy marcada por el ya conocido "problema español", que circunda las páginas de José Martínez Ruiz, Pío Baroja, Miguel de Unamuno, Ángel Ganivet, Antonio Machado, Ramiro de Macztu, Ramón María del Valle-Inclán o José Ortega y Gasset. La mayor parte de las obras de esta selección de autores demuestra un interés relevante por el paisaje como vehículo de transmisión de cultura, del mito castellanista, de la identidad, en definitiva, española. José Martínez Ruiz comenzaba, por ejemplo, el prólogo de El paisaje de España visto por los españoles (1940: 7) con las siguientes palabras:

En estas páginas nos proponemos hacer algunos comentarios sobre el paisaje en las diversas regiones españolas. Y claro está que tal materia del paisaje en una literatura va ligada a otro problema interesante. ¿Cómo ha nacido el gusto por el paisaje, por la Naturaleza, por los árboles y por las montañas en la literatura? Lo que a nosotros nos interesa ahora es España.

De este modo, tal y como expone Dolores Romero López (1998: 76-77), «la naturalización de Castilla como metáfora geográfica cuyo equivalente político se hizo coincidir con una nación, un territorio, una raza, una lengua, una cultura, es equivalente a la naturalización del paisaje extremeño, gallego, vasco y catalán». La reflexión sobre la identidad nacional se sucede de mancra simultánea a la de la identidad regional. Y estas dos reflexiones conjuntas acaban por confluir también en una problematización del llamado "canon nacional" finisecular por oposición a un canon regional, a partir de las relaciones existentes entre ciertos textos escritos en gallego, vasco, catalán, extremeño o andaluz y la oficialidad castellana.

La construcción de la identidad nacional en la España de finales del XIX se resuelve a veces por indagaciones sobre la analogía entre el pasado, la identidad del pueblo y la política, mediante una serie de obras canonizadas en las que se busca el "espíritu del pueblo" (Fox, 1997: 12). Todas ellas comparten el postulado de que en la lengua, la literatura y el arte se expresan configuraciones del mundo que definen ese espíritu, de que existe una historiografía común de la continuidad, así como una misma mentalidad nacional (de origen castellanófilo, por supuesto) ${ }^{5}$. A pesar de ello, las palabras de Pella i Forgas en la revista La Lectura nos demuestran cómo también en Cataluña se da una defensa de lo nacional, asociada al reconocimiento de la fuerza que adquiere el país en los momentos de crisis. Para Pella i Forgas el mito nacionalista, en general, suele aparecer en momentos de conflicto, bien cuando se percibe una amenaza a los valores que definen la identidad colectiva, o cuando las circunstancias críticas reclaman la formación de una identidad nueva:

Los mitos nacionalistas [...] son casi siempre la reacción ante los valores de un enemigo, real o supuesto. [...] El conjunto de mitos nacionalistas españoles, los del centro y los de la periferia, tienen, como veremos, una relación compleja. Relación de oposición a menudo, pero también complementaria. Una misma

3.- Quiero incidir ya de manera especial en la trascendencia de Pascoaes en la configuración de ese imaginario colectivo peninsular, no sólo a través de su obra fundamental, Marânus (1911), sino también a través de la dirección de la revista $A$ Águia.

4.- No podemos olvidar tampoco que gran parte de estos ensayos intercomunica las particularidades de España y Portugal, como nos demuestra Por tierras de Portugal y España de Miguel de Unamuno (1911).

5.- La evolución de la historiografía nacionalista durante la segunda mitad del XIX engendró la concepción de una cultura nacional. Esta concepción de la identidad nacional llegó a institucionalizarse a principios del XX a través de entidades como la Junta para la Ampliación de Estudios (1907), el Centro de Esstudios Históricos (1910), la Residencia de Estudiantes (1910) o la Dirección General de Enseñanza Primaria (1911). 


\section{Ma TERESA VILARIÑO PICOS}

concepción de la nación [...] puede derivar en dos nacionalismos de signo diferente. Un escritor formado en un mitologema determinado puede emigrar con él hacia el nacionalismo rival ( $c f i$ Javier Varela, 1999: 21)

En esta configuración inicial de la identidad nacional peninsular tiene gran trascendencia el pensamiento de otros dos intelectuales catalanes, Manuel Milà i Fontanals ${ }^{6}$ y F. Xavier Lloréns i $\mathrm{Barba}^{7}$, que hallarán el sello característico de cada pueblo, su "espíritu nacional", en el fondo común de ideas y sentimientos, en la "unidad de espíritu y variedad histórica". Destacando el tenor individual de la literatura castellana, «la que presenta, entre las modernas, mayor carácter nacional», y dando por supuesto que los pueblos son como individuos, Lloréns trata de examinar los hechos históricos y los impulsos morales que forman la sustancia o materia nacional, «luego viene el establecer lo que fue asimilado de fuera, así como lo desechado, distinguiéndolo de lo exclusivo de cada temple nacional. Finalmente, habrá que cotejarlo todo para que no se diga diferencial lo que es común a varias gentes o naciones» (Varela, 1999: 27).

Por otra parte, la difusión de ciertas revistas constituirá un pilar fundamental en la configuración del imaginario colectivo nacional y peninsular. En efecto, en este peninsular destacan por esos años Ia lectura. Revista de ciencias y de Artes, fundada por Francisco Acebal en $1901^{8}$ y, sobre todo, Alma española ${ }^{9}$, que, como buena revista militante, adoptó como cabecera la bandera de España, inaugurándose con «Soñemos, alma, soñemos» de Benito Pérez Galdós, la línea que abre los estrechos vínculos entre identidad nacional y paisaje:

Una nación europea no puede ofrecer a las miradas del mundo, en pleno siglo XX, el espectáculo de las estepas desnudas que dan idea de la ancianidad trémula, pecosa y cubierta de harapos. Preciso es desencantar el viejo terruño, dándole con las aguas corrientes, la frescura, amenidad y alegría de la juventud: preciso es vivificar la tierra, dándole sangre y alma, y vistiéndola de las naturales galas de la agricultura. No queremos nada que sea imagen del yermo solitario, ni tristeza ni sequedad de calaveras mondas. En nombre del bienestar público y de la belleza, inundemos las estepas áridas. No queremos fealdad en ninguna parte, sino hermosura que nos enamore de nuestros campos, para que en ellos podamos vivir y gozar de cuanto da la Naturaleza: lozanos plantíos, risueños bosques, deliciosas alquerías, donde hallemos el ejercicio sano y la paz del alma. Un país reconcentrado en poblaciones oscuras y pestilentes, es un enfermo de congestión crónica. La vida se estanca, la sangre no circula, y el tedio urbano, grave dolencia, estimula todos los vicios (8 de noviembre de 1903). ${ }^{10}$

Tiene particular interés la serie de artículos que Alma española dedicó a las distintas "almas" de España (obsérvese que la serie queda circunscrita a la península ibérica e islas adyacentes, sin la inclusión de ninguna "alma" americana), tal y como se anunció en el primer número del 8 de noviembre de 1903: "Comenzaremos pronto la inserción de la interesante serie de trabajos que a continuación se expresan: Alma montañesa, por José M. de Pereda; Alma valenciana, por Vicente Blasco Ibañez; Alma gallega, por Emilia Pardo Bazán; Alma aragonesa, por Mariano de Cavia; Alma catalana, por Juan Maragall; Alma vascongada, por Miguel de Unamuno; Alma mallorquina, por M. de los Santos Oliver; Alma castellana, por Santiago Alba; Alma andaluza, por José Nogales, \&c.» (1903: 10). De los artículos entonces

6.- Vid. la "Oración inaugural" que Manuel Milà i Fontanals pronuncia en la Universidad de Barcelona con motivo de la apertura de curso del año 1854 a 1855 , acerca de la literatura española.

7.- "Oración inaugural... apertura del curso 1865-1866", en De la poesía heroico-popular castellana (1874), Barcelona, 1959.

8. - La revista permanece en vigor hasta 1920 y en ella colaboran los miembros del Centro de Estudios Históricos sobre temas de literatura y cultura nacionales. En 1910 la editorial de la revista lanza la serie de Clásicos castellanos. El mismo Francisco Acebal publicará dentro del marco de la revista su "Alma asturiana".

9.- Alma Española se publicó durante seis meses en Madrid (el primer número sale el 8 de noviembre de 1903 y el número 23, y último, el 30 de abril de 1904). Su editor inicial fue Gabriel Ricardo España y entre los autores que más colaboraron en la revista se encontraban Francisco Acebal, Jenaro Alas, Pío Baroja, Emilio Bobadilla, Manucl Bueno, Manuel Carretero, José Francés, Luis Gabaldón, Ramiro de Macztu, José Martínez Ruiz (hasta el número 13), Gregorio Martínez. Sierra, Ramón Pérez de Ayala y Luis de Tapia.

10.- En <http://www.filosofia.org/hem/190/alm/ae0101.htm>. 


\section{PAISAJES, GEOGRAFÍA LITERARIA E IDENTIDAD NACIONAL}

anunciados no llegaron a publicarse los correspondientes a las "almas" montañesa, gallega y castellana (la aragonesa fue escrita por Royo Villanova, y no por Mariano de Cavia) y además se dedicaron artículos a nuevas "almas" no contempladas en aquel anuncio, como las asturiana, riojana, granadina y murciana. Por el contrario, permanecieron en el olvido otras "almas" que, por analogía, habrían podido ser tenidas en cuenta: extremeña, canaria y navarra.

La identificación de ese continuo peninsular, centrado de manera muy generalizada en Castilla, provoca reacciones diversas en el último tercio del XIX, en el marco de la Renaixença catalana. Por este motivo, el intelectual Víctor Balaguer advertía del grave error cometido por los historiadores al interpretar Castilla como metonimia de España, señalando el hecho de que «España es un compuesto de diversas nacionalidades. Hoy son provincias las que, hace pocos siglos aún, eran reinos y naciones»" ${ }^{11}$. Balaguer explica en un artículo de La Lectura que el alma del pueblo catalán resulta de la agregación del factor orgánico de la raza y de sus caracteres, influidos por el medio en que viven, del factor histórico y el peso de la tradición secular, la incidencia del presente y el horizonte del porvenir, y del factor legal, que tiene en cuenta la representación de la personalidad civil de los individuos, su manera de ser y sus propias necesidades (La Lectura, I, 1902, 1: 12-13).

Esta reivindicación del papel catalanista en el ámbito totalizador de la península cobrará más sentido aún con el crecimiento de lo catalán en los años siguientes al desastre colonial del noventa y ocho, pues, tal y como sostiene Pierre Vilar, fue «el deseo frustrado de forjar el grupo español a imagen de la nación moderna, sobre la industria y el mercado nacional el que lanzó a los doctrinarios y a los hombres de acción catalanes hacia los sueños históricos de un Estado propio y de una nación catalana» ( $c f r$ : Fox, 1997: 79). A Vilar y a Balaguer se suman nuevos intelectuales que luchan por su individualismo cultural; es el caso de la reivindicación establecida por Bartomeu Robert i Yarzábal en "El catalanismo en el concepto naturalista" (La lectura, 1902):

Se echa de ver en la vida del antiguo Principado la acción simultánea y conjugada de tres factores: uno, propiamente orgánico, cuya investigación cae de lleno en la esfera del naturalista, representada por la raza en toda la amplitud de sus caracteres distintivos, pero influida por el medio en que vive; otro, histórico, que engloba su tradición a través de los siglos y es prensa de su presente y esperanza de su porvenir, y otro es su Derecho, representación genérica de su personalidad civil que él mismo se ha dado, en cumplimento de su manera de ser y sus propias necesidades. De esta trinidad resulta lo que podríamos llamar el alma del pueblo catalán (en Santiago Izquierdo Ballester, 1993-1995).

El "problema" catalán, al lado del problema de España, edifica un concepto de nación fundamentado en religiones diversas, distintas razas y diferentes idiomas vernáculos. L'Avenç (1881-1893) y Joventut (1901-1906), del mismo modo que lo hacía Alma española, admiten en sus páginas las proclamas de modernistas como Pompeu Fabra, Santiago Rusiñol, Joan Maragall, Ramón Casas, Joan Brossa o Pere Corominas, que asumen, en mayor o menor medida, el término catalanisme como reflejo de su identidad y como expresión de la renovación de la cultura, relegando cl término nacionalisme para un sector más tradicional. La semilla del renacimiento catalán se fundamentará en la pagesia, en la relevancia del paisaje condensado en el poder de la tierra y de la agricultura (Fox, 1997: 79). Las palabras de Maragall en "La patria nueva" (1902) reclaman la importancia del catalanismo como redentor del españolismo, ensalzando la diferencia lingüística, por supuesto, y la vitalidad de un paisaje propio. Por otra parte, el concepto de nación (o patria) para Cataluña supera las fronteras regionales, e incluso peninsulares, viajando al otro lado del océano a través de la imagen del expatriado, del emigrante, tan frecuente en los textos de Rusiñol ${ }^{12}$.

11.- Algunos críticos han señalado la importancia de Valentí Almirall (1841-1904) en la constitución de un nacionalismo catalán, creando una identidad nacional catalana a través de la historia y de la literatura en contraposición con la cultura castellana.

12.- Dolores Romero (1998: 65) hace referencia también a la escuela mallorquina (Miquel Costa i Llobera, Joan Alcocer) y a la valenciana (Teodoro Llorente). 


\section{$M^{a}$ TERESA VILARIÑO PICOS}

Si nos trasladamos con los trabajos de Fusi Aizpurúa (1984: 31) hacia el País Vasco vemos cómo la transformación de la idea de una identidad en la ideología de un movimiento nacionalista encuentra sus orígenes en los cambios sociales y económicos que experimentó Vizcaya a lo largo de 1880-189013. Si bien es cierto que algunos pensadores, como Sabino Arana Goiri (1865-1903) ${ }^{14}$, consideraban que los rasgos de la identidad vasca estaban basados en la etnia, en el euskaldunismo y en la catolicidad, mediante la raza, la lengua, el gobierno, las leyes, el carácter y la personalidad histórica ${ }^{15}$, también es cierto que los grandes nombres de intelectuales y artistas vascos nacidos en torno a 1863-1873, como Miguel de Unamuno, Pío Baroja, Ramiro de Maeztu, Ignacio Zuloaga, José María Salaverría o Francisco Grandmontagne, consideran lo vasco como inseparable y constitutivo de la nacionalidad española.

En esta visión general quiero destacar también la publicación en Galicia de la revista Ilustración gallega y asturiana (1879-1882), dirigida por Manuel Murguía, que dedicaba una sección entera a la "Galicia pintoresca", así como al rexionalismo (1885-1915) del mismo Murguía y Alfredo Brañas y al "atlantismo" de las Irmandades da fala (1916) ${ }^{16}$. Para Murguía el gallego, por pertenecer a una raza celta (aria), fundido desde siempre con la tierra, ha desarrollado también un amor superior hacia ella por contraposición a otras razas peninsulares, como la semita-africana de la mitad sur de la península, proclives a la anarquía. El rexionalismo se extiende como alternativa periférica frente a la hegemonía castellano-centralista.

La aparición del liderazgo intelectual del Grupo Nós, como comenta Craig Patterson (1998), implica, entre otras cosas, que «do mesmo xeito que a Xeración do 98 volveu a vista ó Século de ouro, [Galicia] volveu a vista á poesía de Rosalía de Castro e Eduardo Pondal, no que viría ser unha das manifestacións da procura de certa identidade nacional que resistise o paso do tempo». Y junto al casticismo, al catalanismo y al euskaldunismo, se evidencia en Galicia el galleguismo, el enxebrismo, con una gran ligazón, por supuesto, a la fuerza de la naturaleza, la tierra y la raza.

Mientras tanto, en Portugal surge la presencia desde 1890 de Eça de Queirós y de los realistas portugueses, del Neogarretismo ${ }^{17} \mathrm{y}$ del Saudosismo ${ }^{18}$ de Joaquim Teixeira de Pascoaes para quien el alma lusíada halla su origen en la fusión de los antiguos pueblos que se encontraron en la Península, distinguiéndose así de las otras almas patrias desde el inicio, por tener un carácter nacional muy riguroso.

Si La lectura o Alma española habían colaborado a la institucionalización de un canon nacional desde sus enclaves espaciales, la lucha por un resurgimiento nacional se efectuaría en el Portugal de la primera década del siglo XX a partir, sobre todo, de la revista quincenal de literatura, filosofía y ciencia social A Águia (1910-1932). Pascoaes expone como «o fim desta revista, como órgão da Rennascença Portuguesa, será, portanto, dar um sentido ás energias intelectuais que a nossa Raça possui; isto é, colocá-las em condições de se tornarem fecundas, de poderem realizar o ideal que, neste momento histórico, abrasa todas as almas sinceramente portuguesas -criar um novo Portugal, ou melhor ressuscitar a pátria portuguesam arrancá-la do túmulo onde a sepultaram alguns séculos de escuridade física e moral, em que os corpos definharam e as almas amorteceram» (1988: 35). A Águia busca «trazer á tona os elementos nacionais portugueses, procurando o renascimento

13.- El nacionalismo vasco fue originariamente un fenómeno político urbano y bilbaíno, caracterizado por la reacción de una identidad cultural tradicionalista, amenazada por la abolición de los Fueros de 1876, la industrialización, la inmigración masiva de trabajadores no vascos y la conflictividad que trajo la nueva sociedad industrial.

14.- Fundador del periódico El Bizkaitarra (1893-1895), y de la revista Euzkadi (1901).

15.- Vid. Jesús Azcona (1984).

16.- Vid. Manuel Mourelle de I.ema (1999).

17. - La obra de Almeida Garret, autor de Viagens na minha terra (1844), suponía una exaltación de lo pintoresco del paisaje portugués y del sensualismo y fatalismo de su raza.

18.- Cfr: E. Lourenço (1978) o Motta Oliveira (1990). 


\section{PAISAJES, GEOGRAFÍA LITERARIA E IDENTIDAD NACIONAL}

da identidade da Nação» (1988: 10). La estrecha relación entre identidad y paisaje se evidencia en uno de los números publicados en 1913 de A Águia, dibujándose allí una serie de elementos destacados que sirven como inspiración temática del concepto de nación y que reflejarían, según Pascoaes, «a feição original do gênio português» (vol. V, 2." serie, 1913, 112). Entre ellos sc señalan la idea de comunicación apasionada con las cosas, el panteísmo, el silencio, las imágenes de la luna, del yermo, de la nieve, de lo remoto y de la ausencia o la soledad.

\section{Paisaje e identidad nacional}

Dentro de todo este entramado político-social y literario, Helena Carvalhão Buescu (1996: 193) nos da la herramienta para entender que «a paisagem é, sobretudo, um elemento cuja culturalidade é inegável». El imaginario colectivo que Francisco Ayala (1996: 27) remonta a aquellos valores significativos compartidos que integran cada comunidad dentro de una concreta tradición cultural, la "configuration interdiscursive» ${ }^{19}$ de la que hablaba Foucault en Les Mots et les Choses encuentran asidero en la delineación del paisaje.

La etimología del propio término paisaje nos conduce a una comprensión del mismo como «pedazo de país» (C. Guillén, 1996: 71). La caracterización del término paisaje por Beaugué (1556) y D. Bartoli (1657), que lo comprenden como un «conjunto de características de una localidad, visibles desde un determinado puntom incide en el vínculo entre paisaje y sujeto e implica, en términos de Buescu (1996: 196) «aquilo que o sujeito nela reconhece é uma culturalidade que tem a ver com a sua dimensão temporal, porque só através dessa dimensão se podem escrever uma história, uma tradição e uma convenção semantizada». Ese innegable culturalismo lo reconoce también Nicolás Ortega Cantero (2004: 9) cuando manifiesta que todo paisaje es al mismo tiempo una realidad formal y una imagen cultural: «el paisaje no es sólo una configuración formal susceptible de explicación; es también un conjunto de valores, cualidades y significados que, con todas sus dimensiones culturales, requieren ser comprendidos» (2004: 9).

En el paisaje nos hallamos, como sostiene Claudio Guillén (1996: 72), ante «un indudable cruce de la historia de la literatura con la de la pintura, pero sobre todo ante la subordinación de ambas a lo que ciertos estéticos del siglo pasado, maestros de Heinrich Wölfflin, llamaban la "historia de la visión"», porque es precisamente la mirada humana lo que convierte cierto espacio en paisaje, consiguiendo que una porción de tierra (pedazo de país) adquicra por medio del arte calidad de signo de cultura, no aceptando lo natural en su estado bruto sino convirtiéndolo también en cultural ( $c f$ : Claudio Guillén, 1996: 68).

Desde la tradición de la escuela alemana, que entendió los paisajes como plasmaciones morfológicas del territorio, como "paisajes naturales" ("geografía física") y "culturales" (geografía humana), hasta la escuela de Francia, en donde el concepto paisaje se vuelve un objeto espacial y un "artefacto" geográfico, producido por la adaptación del hombre al medio y del medio al hombre, una expresión del género de vida agrario y urbano, una decantación de la relación entre civilización y su lugar, o los estudios de la escuela rusa (la ciencia del geosistema), en la geografía española, el término ha sido utilizado de manera científica desde los años veinte (Dantín y Hernández-Pacheco) (con un peso esencial del medio físico) con un sentido cultural. El paisaje aparece como un acumulador, en términos de Jesús García Fernández, como un "totalizador histórico", aglutinador de configuraciones territoriales. Asimismo, como comenta Martínez de Pisón (en Ortega Cantero, ed., 2002: 17) ${ }^{20}$, «el paisaje muestra vida porque posee energías, fuerzas y es un sistema de relaciones horizontales (geográficas) y verticales (ecológicas) entre sus componentes, sus conjuntos y con las áreas vecinas y con la región en que se incluye» y manifiesta lo que podríamos llamar "cultura territorial de una sociedad".

19.- Se trata de un conjunto de textos teóricos y producciones estéticas que descansan en el mismo sistema conceptual.

20.- Vid. también Martínez de Pisón, (1998) y Martínez de Pisón y Sanz Herráiz, eds., (2000). 


\section{$M^{a}$ TERESA VILARIÑO PICOS}

Los contenidos culturales que se asocian a la morfología del paisaje son de dos tipos: los integrados por el propio paisaje (naturales, antrópicos y monumentales) ${ }^{21}$ y los otorgados desde fuera, es decir, las valoraciones artísticas, científicas, literarias, pictóricas y naturalistas, que enseñan a ver de determinados modos estos paisajes. La geografía cultural hace «hablar a los paisajes, muestra los diversos niveles de cultura y manifiesta los valores que fundamentan la acción social, colectiva o propia de un grupo o elite» ${ }^{22}$.

Dentro del marco teórico del paisaje me resulta de gran utilidad el término país verbal de Claudio Guillén para referirme a aquellos paisajes transmitidos exclusivamente por lo literario ${ }^{23}$. El marbete país-paisaje verbal será efectivo para explicar cómo la crisis de identidad de la juventud del 98, asociada a la crisis de nacionalidad (Varela, 1999: 148) y a la nacionalización de la literatura, corre pareja igualmente a la nacionalización del arte y a la búsqueda de las fuentes de la literatura nacional ${ }^{24}$. La tarea de sus representantes será la de esclarecer el "cspíritu" de la vieja España, «el genio castellano» (Azorín), «el espíritu inmortal» (Menéndcz. Pidal), cl «misterio de nuestra alma española» (Ganivet) o el «alma castellana» (7uloaga). Todos estos pensadores creen de manera generalizada en la entidad de un sujeto colectivo, pueblo o nación, con tonalidades peculiares, que se concretan en la morfología física del suelo, la lengua, las costumbres, la historia o las tradiciones y el paisaje.

Pintores, y escultores, crean la iconografía de los escritores y, al lado del paisaje verbal, surge de manera indisociable el paisaje-decorado, ornamento o escenario, esto es el Parergon de Thomas Blount: «paisaje o complemento, que es una expresión de la tierra, por medio de montes, bosques, castillos, valles, ríos, ciudades, etcétera, en la medida en que puede mostrarse antes del horizonte. Todo lo que en pintura no es parte de su cuerpo o argumento es paisaje, parergon o complemento" (en Guillén, 1998: 100).

La idea muy arraigada en España, de que el arte y el paisaje revelan a menudo el carácter nacional tuvo su influencia en la formación de la primera escuela de paisajistas españoles y en la recuperación y revalorización de la obra de El Greco y Velázquez, entre otros, bajo la tutela de las ideas institucionistas sobre la regeneración del país, mediante el descubrimiento de esa conciencia nacional auténtica e "intrahistórica" (Fox, 1997: 157)25.

Esta manera particular de observar la realidad nacional tiene su origen en el libro La España negra (1898) de Regoyos, que traduce parcialmente los textos publicados por Verhaeren en

21.- Los naturales son aquellos valorados por el análisis científico y por la percepción objetiva de los hechos; los antrópicos son los resultantes de una implantación territorial secular y los monumentales llegan sobreimpuestos desde fuera, añadiendo elementos paisajísticos muy característicos.

22.- Vid. P. Claval (1992 y 1996) y J. L. Piveteau (1994).

23.- Sobre el concepto de paisaje, su evolución histórica y, sobre todo, su sentido filosófico, vid. Julio Caro Baroja (1981).

24.- Además de por el Romancero, Berceo o el Arcipreste de Hita predomina una predilección por el Greco, Velázquez, Goya y Berruguete, por su arte austero, realista y castizo. El siglo XVI sería, para Ganivet, el momento privilegiado en que se fragua la nacionalidad española, reflejada en la lengua, las artes y las letras. El carácter austero, la voluntad y la acción vendrán a representarse en las figuras del hidalgo, el conquistador, el místico, el guerrero o el inquisidor: El Cid, Santa Teresa y Cisneros son, de este modo, arquetipos de la raza castellana.

25.- En este sentido, la Historia de la pintura española de Cossío (1985) constituye el primer texto sobre pintura española, escrito con una finalidad didáctica, en el que se estudia lo que es específicamente español para ir descubriendo el carácter de la pintura nacional. Y es Carlos de Haes, iniciador de la pintura de paisaje en España, quien opina en 1860 en su Discurso de recepción en la Academia de San Fernando, que las gentes prefieren la pintura de Historia, porque «necesitan la reproducción de su propia imagen y los dramas en que son actores» (cn Claudio Guillén, 1996: 68). Para un análisis de la importancia de la pintura de Carlos De Haes, así como de Berrugete, en la delineación paisajística de la España peninsular, puede consultarse María del Carmen Pena (1982). 


\section{PAISAJES, GEOGRAFÍA LITERARIA E IDENTIDAD NACIONAL}

la revista belga L'Art moderne ${ }^{26}$. La imagen construida por las perspectivas de Regoyos y Verhacren es la de una España con un futuro de horizontes cerrados, en la que predomina lo decrépito, lo sangriento o lo fúnebre, en una configuración estética de lo sórdido ( $c f r$ : Lozano, 2000: 39). Del mismo modo, Ignacio Zuloaga, como Gutiérrez Solana, crean su arte fascinados por un ambiente que se les impone con fucrza obsesiva, por ciertas formas de vida populares que entienden como elocuentes manifestaciones de un carácter nacional (Lozano, 2000: 768). Zuloaga, por ejemplo, cultiva el paisaje urbano y el panorámico, siempre inspirado en las tierras de la "España esencial", en sus paisajes de la meseta, de Aragón, Navarra o La Rioja ${ }^{27}$. En toda su obra, Zuloaga huye de una geología estática, en su búsqueda de un equilibrio entre paisaje y figura, reflejo del pueblo español y su carácter castellano, austero, duro, "pueblo capaz, de inspirar a Unamuno o Azorín para evocar una España no ya pasada, sino eterna, la que sucña objetivos absolutos para la empresa humana y mantiene la existencia en carne viva de sentimiento trágico» ( $c f r$ : Lafuente Ferrari, 1972: 276 y 1990) ${ }^{28}$. Su estilo se basa en la simplicidad y en la acentuación del carácter, tal y como le comenta a Juan Pujol en una de sus cartas:

En un cuadro no busco atmósfera, distancias, ni busco sol ni luna. Busco carácter, penetración, psicología de una raza, emoción, demostración de una visión algo romántica. Busco el alma a través de un realista soñador. Busco la línea, el arabesco, la armonía, la visión personal y la simplificación. Busco la fuerza del atrevimiento, la franqueza de las ideas, el gritar fuerte y profundo, el sintetizar el alma castellana, el sacrificar muchas cosas para hacer valer una esencial (en "El pueblo vasco" y en "Alma castellana", febrero de 1912). ${ }^{29}$

Pero será este interés por el castellanismo, equivalente a austeridad, el que se convierta en el principal objetivo de la crítica de Juan de la Encina en su artículo "Una visita a Zuloaga", publicado en La voz (14 de septiembre de 1925).

Una parte de su pintura -una parte de la que ha producido en estos últimos quince años desde 1910- no ha dejado de irritar nuestra sensibilidad por su falta de fineza. EI gran estilo de Zuloaga iba degenerando en manera. Abusaba un poco de cierta fórmula españolista que nunca hemos podido tragar, porque no

26.- En 1924 vuelve a ser reeditado en los "Cuadernos literarios" de La Lectura con el título de La España negra de Verhaeren.

27.- "Calle de una ciudad vieja castellana" (1894); "Mis primas" (1903); "Mujeres de Sepúlveda" (1909); "Retrato de Maurice Barrès con Toledo al fondo" (1913); "Retrato de Ramón del Valle-Inclán" (1931); "Paisaje de El Escorial" (1932); "Catedral de Segovia" (1938); "Alcázar de Segovia" (1938). Zuloaga fue además el retratista del 98, iniciando su serie de retratos hacia 1917 con el inacabado de José Ortega y Gasset, con fondo de El Escorial. En 1919 retrató a Gregorio Marañón, ante un paisaje de colinas terrosas y en 1925 a Miguel de Unamuno, introduciendo una mesa con libros y objetos personales en el esquema habitual del modelo sentado, sosteniendo un libro (su obra) en la mano. De 1931 es su "Retrato de Ramón Pérez de Ayala" y de 1941, "Retrato de Azorín", en donde se recrea al escritor sentado, con la cabeza como centro de composición, junto a una mesa con sus obras, sosteniendo también, al igual que Unamuno, su libro Pensando en España.

28.- Obras entre 1910 y 1912: "La víctima de la fiesta", "La familia de tío Daniel", "El cristo de la sangre", "El cardenal", "La cortesana española", "La corrida en Sepúlveda". De 1917 son los paisajes realizados en Zumaya. Los temas segovianos de su obra primeriza se extienden alrededor de los años 1921, 1926, 1930 y 1932 a Castilla, Aragón y Navarra (vid. su "Paisaje de Calatayud" (1930). Bajo la influencia de Cézanne y su construcción del paisaje por planos, Zuloaga reproducirá un sentimiento de tierra árida, visible en "Palacio de Peñaranda del Duero" (1940), en donde a la simbolización añade elementos narrativos, adoptando, en muchos de sus paisajes, la forma de raras escenas teatrales.

29.- Para Salaverría, Julio Antonio quería convertirse en el escultor de la raza, aunque también se dijo que su arte no encarnaba el sentimiento de "nacionalidad", es decir «que no resultaba ser suficientemente castellano, como lo

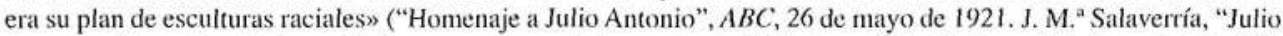
Antonio, el escultor de la raza", Caras y caretas, 4 de agosto de 1917. Juan de la Encina, Julio Antonio, Madrid, 1920. A. Ballesteros de Martos, Artistas españoles contemporáneos, Madrid, s. d.). El escultor de Castilla fue, sin duda, Victorio Macho (realizará los retratos de Baroja, Unamuno y Valle-Inclán). 


\section{$M^{\mathrm{a}}$ TERESA VILARIÑO PICOS}

estamos dispuestos a admitir fácilmente que lo típicamente español sea lo bárbaro, lo exento de pulidez y distinción refinada, y que la corambre, el ajo y el pimentón sean los símbolos de nuestra espiritualidad.

Zuloaga, en fin, es, para Javier Varela (1999: 171), el representante más destacado de la pintura nacionalista española porque en el eibarrés se apreciaban el tipo, el carácter nacional y lo que denomina «la pintura esencialmente española».

El mito castellanista, también paisajístico, está profundamente arraigado en el nacionalismo español. La nación, Castilla, es ante todo un carácter y un paisaje, apenas tiene que ver con la organización política y se constituye en el magno problema de problemas, «supremo concepto de conceptos ${ }^{30}$. En este sentido, Francisco Ayala (1996: 26) arguía que los cuadros de paisaje se produjeron respondiendo al espíritu de época dentro de una concreta coyuntura histórico-cultural que implicaba a su vez una imago mundi determinada: «la puesta en valor del paisaje castellano [...] ilustra bien [...] lo que en términos generales quiero decir: gracias a estos artistas de la palabra, algo que antes parecía feo -o mejor, que no existía como paisaje- se reveló de entonces en adelante revestido de insospechada belleza» (1996: 25).

Los juicios sobre España y lo español se inspiran en una inicial rebeldía, un inconformismo que busca la palingenesia de la patria mediante viajes por las tierras, los pueblos, las ciudades, los viejos monumentos, en un constante recorrer los caminos de España ( $c f r$ : Abellán, 1996: 522) ${ }^{31}$. La preocupación por el paisaje se demuestra en la recreación de los lugares más diversos de la geografía nacional (Levante, Vasconia, Galicia, Andalucía y Madrid, aglutinante, este último, de todos los demás). Desde Madrid los autores descubren Castilla con sus llanuras inmensas, sus lomas pobladas de encinas, con sus ríos bordeados de chopos, con sus ciudades silenciosas, casi muertas, donde se guardan inéditos tesoros artísticos y olvidados recuerdos históricos de un pasado glorioso.

"La mitología del 98", la preocupación por la España ideal, la convicción compartida de que España está sin terminar, y que hay que terminarla para dar un remate bello y honroso a nuestra historia, preocupa a Baroja, Azorín y a Maeztu, siguiendo las ideas de Ganivet en su Idearium español. Como expone Claudio Guillén (1996: 81), "Castilla de Azorín, o Por tierras de Portugal y España de Unamuno, [...] tienden a ser, ¿cómo resumirlo?, meditaciones; o si se prefiere, ensayos, sensu lato, cuyo objeto de interpretación es el entorno natural, y que acaban siendo descripciones del autor o del tipo humano nacional. El paisaje de Unamuno es el decorado de su propio existir y de los afanes que quiere compartir con sus lectores».

El tema de España se convierte en objeto de reflexión continua en obras como El problema nacional (1899), de Macías Picavea, Hacia otra España (1899), de Ramiro de Maeztu, Del desastre nacional y sus causas (1899), de Damián Isern, el Idearium español (1901), de Ganivet, En torno al casticismo (1902), de Miguel de Unamuno, Reconstitución y europeización de España, de Costa (1902), El alma castellana, de Martíne z Ruiz (1902) y Psicología del pueblo español, de Altamira (1903).

Para José Martínez Ruíz ${ }^{32}$, otro de los inventores, según Fox, de la «identidad colectiva nacional» (1997: 132), lo que da la medida de un artista es su sentimiento de la naturaleza, su

30.- Vid. F. Rivera Pastor en un artículo de 1921 que titula precisamente “¿Es España una nación?”.

31.- Y, por supuesto, 1973.

32.- La voluntad (1902), Antonio Azorín (1903), Las confesiones de un pequeño filósofo (1904), España (1909), "Castilla", en $A B C$ (15 de abril de 1909), "El problema de España" (21 de mayo de 1911), "España", en Fantasías y devaneos, "Epílogo en Castilla" a Lecturas españolas (1912), El paisaje de España visto por los españoles (1917). Según el Azorín de 1910 no es hacia la europeización hacia donde los españoles deben mirar sino crear una conciencia de su propio ser a través de la continuidad nacional, de origen castellano ("La continuidad nacional", en $A B C, 21$ de mayo de 1910). 


\section{PAISAJES, GEOGRAFÍA LITERARIA E IDENTIDAD NACIONAL}

emoción del paisaje ${ }^{33}$. En sus Lecturas españolas (1912), al final del capítulo "La España de Gauticr", podemos leer:

\footnotetext{
Vivamos nuestro tiempo; pero si somos artistas, si sentimos algo ante el paisaje y en las viejas ciudades, tratemos de expresar en unas páginas de prosa o en unos versos -como hizo Gautier- la impresión que en nosotros produce esta llanura parda y solitaria de Castilla, esta callejuela con sus tiendecillas de abaceros y regatones, este viejo palacio con los cristales rotos y polvorientos, cerradas las ventanas, con su jardín de adelfas, rosales y cipreses, obstruidos los viales por los hierbajos, saturado el ambiente por denso olor a humedad, llenas de hojas las aguas inmóviles, negras, de una fuente (1975: 955).
}

El impulso germinal de Lecturas es el de la «curiosidad por lo que constituye el ambiente español», captado en su "paisaje, letras, arte, hombres, ciudades, interiores» (I, 1975: 914). El tema central azoriniano es nuevamente el de la "continuidad nacional" por los españoles (1917) constituye un asunto de gran atractivo el concepto geográfico y literario de Castilla (F. Abad, 1996: 108) ${ }^{35}$. En La voluntad, por otra parte, se establece una reflexión entre el paisaje y el carácter del alma española, que parece más bien castellana. De hecho «acabará por convertir la literatura española en literatura castellana en el marco de esta reflexión, y la picaresca en uno de sus principales exponentes» (cfi: F. Cabo, 2001). Las ideas azorinianas se basan en un determinismo a lo Taine (y sobre Taine volveremos más adelante al hablar de Unamuno) que había desarrollado ya en La evolución de la crítica (1899). Hay un intento de situar la sociedad española en su «medio, en su sociedad, en su instante».

Una de las dimensiones fundamentales de la obra de Unamuno es la que contribuyó a la definición de una comunidad española imaginada, asociada con una ideología política, que, en palabras de Fox (1997: 111), «ha pasado casi desapercibida para los estudiosos» ${ }^{36}$. Decía Unamuno en "Sobre el marasmo actual de España" que «España está por descubrir, y sólo la descubrirán españoles europeizados. Se ignora el paisaje y el paisanaje y la vida toda de nuestro pueblo. Se ignora hasta la existencia de una literatura plebeya...» $(I, 866)$. Con el fin de reflexionar sobre el concepto de nación y la casta histórica española el autor vasco alude al voluntarismo nacionalista de "Qu'est-ce qu'une nation?" (1882) de Ernest Renan, y llega a la conclusión de que la cultura nacional siempre se ha fundamentado en una comunidad de intereses y se ha enriquecido por la asimilación de ciertas influencias extranjeras. Unamuno introduce en En torno al casticismo un capítulo sobre cómo la geografía y el paisaje influyeron en el espíritu castellano. En Salamanca se hundió en el paisaje de Castilla que provocó en él un proceso de castellanización y le proporcionó otra perspectiva para entender el pasado español. Hay una asociación grande entre el concepto de intrahistoria y su sentimiento de la naturaleza, en el que los representantes de la tradición eterna son campesinos, labriegos o pastores. En cuanto a la meseta, se destaca lo inhospitalario y lo expansivo de su tierra, su clima extremado (nueve meses de invierno y tres de infierno), que provoca la existencia de campos sin fronda y sin arroyos, pardas encinas y tristes pinos: "Qué hermoso, sin embargo, el paisaje lleno de cielo, pero monótono y uniforme en sus contrastes de luz y sombra. No despierta este paisaje sentimientos de alegría de vivir, no hay comunión con la naturaleza, es un paisaje en que se achica el hombre» (OO. CC. III, 211-212). La naturaleza es reveladora de la tradición eterna que repercute en la personalidad del castellano: "Casta de hombres sobrios, de humorismo grave o de socarronería, tienen espíritu cortante y seco, pobre en nimbos de ideas, de ideas uniformes, monótonos como sus bailes y su música» (ibidem).

33.- Azorín identifica a Zamora como ejemplo de la ciudad que representa la España profunda (Lozano, 2000: 52). 34.- Vid. Inman Fox (1988).

35.- También 1987 y 1992.

36.- En torno al casticismo (1895), Tres ensayos (1900), Paisajes (1902) y Vida de don Quijote y Sancho (1905), "País, paisaje y paisanaje", en Ahora, 22 de agosto de 1933, en OO. CC., I, 705, Paisajes del alma, Por tierras de Portugal y España, Andanzas y visiones españolas. 


\section{Ma TERESA VILARIÑO PICOS}

La deuda de Unamuno con Taine se condensa en la problemática de que el medio físico, la raza y el paisaje son las verdaderas causas universales y permanentes de la historia española. En una carta sobre la redacción a En torno al casticismo, incluida en el prólogo de sus OO.CC., III, escribe: «Toda aquella descripción de Castilla, paisaje, etc., responde a las de Taine de los Países Bajos. Leía mucho a Taine, entonces. Y a Carlyle...». En cuanto al paisaje se refería Unamuno a la obra de Taine titulada Philosophie de l'art (1881) en que busca el estado general del espíritu y de las costumbres del pueblo en la pintura (incluyendo paisajes) del Renacimiento italiano y de los Países Bajos, relacionando las obras de tales periodos con las condiciones de raza, de cultura y de modo de vida. En sus ensayos sobre la pintura nacional, el paisaje y el carácter, Taine alude a menudo a las artes españolas. El tipo de raza española, según él, que se manifiesta en la pintura es «endurecido por los vientos de sus tierras y las quemaduras de su sol, tenaz e indómito, ardiendo de pasiones reprimidas, austero, seco». En cuanto al carácter moral, se destacan entre los españoles el sentido el honor, el amor exaltado y la religiosidad. Para Unamuno, el problema de España es en realidad un problema psicológico, mientras que los estudios de Taine se fijan en la realidad social y la psicología colectiva.

De la relación entre pintores y escritores que mencionábamos líneas atrás, las figuras de Regoyos y Verhaeren, así como la de Zuloaga son, sin lugar a dudas, las más analizadas por Miguel de Unamuno. "De Arte pictórica" (1912) (OO. CC., VII: 737-738), por ejemplo, refleja su entusiasmo por la obra de los autores de La España negra, y manifiesta que la España religiosa y trágica, es para él tan española como cualquier otra y «algunos creemos que más aún», en una «incontestable superioridad de la pintura sobre la literatura española» (Lozano, 2000: 33). En cuanto a Zuloaga, reconoce que la contemplación de sus obras le ha servido para «fermentar las visiones que de mi España he cobrado en mis muchas correrías por ella» y que «he ahondado en mi sentimiento y concepto de la noble tragedia de nuestro pueblo, de su austera y fundamental gravedad, del poso intrahistórico de su alma»". Y en "De Arte pictórica", de nuevo, se siente llevado a defender «a mi paisano y amigo el gran pintor vasco Zuloaga, el revelador acaso de lo más hondamente específico y diferencial de la España de hoy, contra los españoles, más o menos europeizantes, que le motejan de estar falsificando la verdad. [...] En rigor es que no hay una sola España, hay varias Españas, ni hay siquiera una sola Castilla, sino varias Castillas, y la España vista y sentida por Sorolla, verbigracia, no es la vista y sentida por Zuloaga, como la España que mejor ha visto Blasco Ibáñez no es la de Baroja o la mía» $(53)^{38}$.

El descubrimiento que Unamuno hace de Zuloaga se extiende, según Calvo Serraller, a Ortega y Gasset, Pérez de Ayala, Azorín y Pío Baroja: «Si, a través de lo que se acaba de reproducir, pensamos en la ansiedad de los noventayochistas por discernir la genuina urdimbre de la identidad española y su reticencia a dejarse arrastrar por la avasalladora modernidad del progresismo burgués, y lo aplicamos a sus ideas artísticas, comprendemos por qué pudieron coincidir con Zuloaga» $(212)^{39}$. Ortega, por ejemplo, en “¿Una exposición Zuloaga?" (1910: 140) indica cómo en la pintura del autor se evidencia por todos lados el "problema español" y un examen de conciencia nacional. Puesto que lo más "glorioso» que puede hacer por el porvenir de su raza un artista hispano es ponerla en

37.- (Vid. "La labor patriótica de Zuloaga", en Hermes, agosto de 1911 y OO. CC., VII, 766). Para un conocimiento más pormenorizado del papel de la revista Hermes en el regionalismo vasco, véase José-Carlos Mainer (1982). Al lado de la revista Hermes, Mainer aborda igualmente la Revista de Aragón (1900-1905).

38.- Tomás Facundo (2000) analiza por extenso la relación de Valle-Inclán, Unamuno y Azorín con la obra de Sorolla, por un lado, y de Blasco Ibáñez, por otro, explicando lo que denomina "mapa de España" de cada uno de los autores a partir de sus opiniones sobre la pintura.

39. - 1917. Artículo "La labor patriótica de Zuloaga" (Hermes): «¿y no es acaso el campo castellano, una proyección del alma del pueblo que lo habita?», p. 95. Y Araquistain escribió que «Zuloaga es el último que pintaría un paisaje para aprehender nada más que el color. Como en las figuras vivas, un paisajes es para él, ante todo un carácter, una fisonomía inanimada en fiunción del tiempo y del país” (El Sol, "El hombre Ignacio Zuloaga", 10 de octubre de 1924). 


\section{PAISAJES, GEOGRAFÍA LITERARIA E IDENTIDAD NACIONAL}

contacto consigo misma, sacudirla y herirla hasta despertar totalmente su sensibilidad. Y un año más tarde, en "La estética de 'El enano Gregorio Botero"”, expone cómo «la historia moderna de España se reduce, probablemente, a la historia de su resistencia a la cultura moderna..., éste es su gesto, su genialidad, su condición, su sino. ¡Un ansia indomable de permanecer, de no cambiar, de perpetuarse en idéntica sustancia! Durante siglos sólo nuestro pueblo no ha querido ser otro de lo que es; no ha deseado ser como otro".

Ganivet pretende alcanzar el mito de la España ideal con la doctrina de que hay que buscar la verdad dentro del propio país, concentrando dentro del territorio toda la vitalidad nacional. En su Idearium español (1897) se manifiesta partidario, como ya habíamos visto en otros autores, de una cerrazón cultural: «Una restauración de la vida entera de España no puede tener otro punto de arranque que la concentración de todas nuestras energías dentro de nuestro territorio. Hay que cerrar con cerrojos, llaves y candados todas las puertas por donde el espíritu español se escapó de España para derramarse por los cuatro puntos del horizonte...».

Su actitud en contra del concepto de nación se vuelve evidente con su apoyo del de "polis autónoma" (Noli foras ire, in interiore Hispaniae habitat veritas).

El caso de Ramón de Valle-Inclán muestra el reconocimiento de las periferias en el marco peninsular. Valle-Inclán, en un artículo publicado en 1919 sobre la pintura vasca, reconoce en España tres regiones bien definidas por el paisaje: la cantábrica (desde Galicia hasta el País vasco), la castellana (las dos Castillas y León) y la levantina (desde Andalucía hasta Cataluña). Y a estas diferencias en el paisaje les asocia Valle unas diferencias en el carácter. La región castellana, por ejemplo, tiene para el autor una expresión mística, de acabamiento, de cansancio. Se trata de una región anclada en el pasado, sin capacidad de decisión en el progreso de un futuro. A diferencia del carácter cerrado de Castilla, y en esto coincide con Ortega y Gasset como enseguida veremos, Valle-Inclán reserva los mayores clogios para la región cantábrica: «el pucblo vasco, y con el pueblo vasco todos los que se asocian al Cantábrico, no se ha desenvuelto aún [...] son primitivos, ésos tienen todavía un sentido juvenil, miran adelante y son impulsados por el logos espermático, por la razón generadora” (en Facundo Tomás, 2000: 93). Por último, la región levantina se convierte en el foco de la ira de Valle-Inclán; la califica de amarga, de gitana y de falsa.

De otro lado, José Ortega y Gasset, como adelantábamos, resulta uno de los pocos autores que busca las manifestaciones de la identidad nacional en el presente. Para Ortega cl paisaje encierra una morfología territorial, contiene ideas, imágenes y una cobertura cultural y vivencial. Toda la ideología de Ortega con respecto a la raza, a la patria y a la nación se reviste de una relación muy estrecha con las consideraciones teóricas sobre el paisaje, que se evidencia en los términos "geografía", región natural, teniendo siempre presente una perspectiva "sobrenacional" de la península ( $c f r$ : Ortega y Gasset, 1916). Lo más importante y distinto en su concepción de la patria con respecto a la mayor parte de los autores anteriores, a mi entender, es su carácter abierto, dinámico, progresivo e inacabado, reconociendo además sus posibilidades de evolución por las luchas ocasionadas en las diferencias étnicas y culturales del territorio peninsular. De este modo, en "Viaje de España" (1910: 527) explica que la patria «no es nunca una cosa hecha, cumplida, hieratizada y perfecta, sino un perpetuo problema, una tarea nunca acabada, una futura realidad, un conflicto entre posibilidades presentes». Y se insiste de este modo en la vitalidad concedida al paisaje como traductor de la identidad nacional, un paisaje que, en su perspectiva, no determina casualmente los destinos históricos (vid. 1925: 373), sino que, junto con «el dato geográfico», es muy importante para la historia, en un sentido, eso sí, opuesto al defendido por Taine. Para Ortega, la geografía funciona como símbolo y síntoma del carácter de un pueblo, puesto que cada raza lleva en su alma primitiva ese ideal de paisaje que se esforzará por realizar dentro del marco del contorno. De manera dependiente a los conceptos de geografía y paisaje, Ortega crea el de "región natural" que califica como «fenómeno matriz de la investigación geográfica» (1921: 259). De esta concepción orteguiana se desprende una especie de idealización del país que, más que con efectividad física real, se reducirá a una 


\section{$M^{a}$ TERESA VILARIÑO PICOS}

construcción mental. La idea de una España única y uniforme, centrada, por ejemplo, en el casticismo, como defendía la mayor parte de los autores del 98, no es más que una «abstracción política e histórica». Y a propósito del casticismo, Ortega clabora toda una reflexión personal en el volumen segundo de El Espectador (1917), refiriéndose a la idea de lo castizo como un corsé normativo y rígido que hay que romper en beneficio de una imagen aperturista de la península. Por este motivo, Ortega critica la «inocente manía panegírica» de defender la patria española a través del casticismo y lo castizo. Esta defensa desemboca ineludiblemente, en términos orteguianos, en provincianismo y aldeanismo. En sus distintos recorridos por los paisajes peninsulares (Asturias, Castilla, Andalucía o Cantabria) y por los de autores como Azorín, Baroja o Unamuno ${ }^{40}$, Ortega expone que lo castizo debe interpretarse de una manera espontánea y no normativa. Las normas, para el filósofo español, son siempre «abstracciones, rígidas fórmulas provisionales que no pueden aspirar a incluir las ilimitadas posibilidades del ser» (1917: 187).

Y si nos trasladamos finalmente a Portugal, Teixeira de Pascoaes comenta en su Arte de Ser Portugués, cómo «A alma pátria é, por tanto, caracterizada pela fusăo que se realizou, na nosa Raça, do princípio naturalista ou ariano e do princípio espiritualista ou semita, e pelas qualidades morais da paisagem que, $\mathrm{cm}$ vez de contrariar a herança étnica, a acentua e fortalece» (80). Y en la revista A Águia, Pascoaes hará descansar parte del alma portuguesa en la saudade, vinculada al paisaje:

Houve un momento em que no meio d'essa confusăo rumorosa e guerreira, se destacou uma voz. proclamando um Povo, gritando a Alma d'uma Raça: foi a voz de Viriato [...] E n'esse momento, mais divino que humano, a alma portuguesa gerou nas suas entrañas, penetradas por uma luz celeste a "Saudade", a nebulosa do futuro Canto Imortal, O Verbo do novo mundo portugués (A Águia, I, 2." Serie, n. ${ }^{\circ}$ 1, 1912).

La saudade, enlazada con el momento histórico, será la esencia espiritual de la raza, constituida por el equilibrio entre el espíritu y la materia, se manifestará en la tristeza, revelará el alma portuguesa en sus manifestaciones más íntimas y delicadas, procurando mostrar los elementos más poéticos: «O Saudosismo representa o culto da alma portuguesa no que ela encerra de novo credo religioso e, de nova emoção poética, em virtude da sua ascendência étnica». El saudosismo surge como un movimiento restaurador de Portugal en la búsqueda de su esencia original y Teixeira de Pascoaes indaga en lo que hay de profundo $\mathrm{en}$ el imaginario portugués para la reconstitución de la nación ${ }^{41}$ : «O sentimento original da saudade é o sentimento da nossa singularidade ontológica, ou seja, da liberdade essencial do ser do homem. Se o ser, por realizar a liberdade, se singulariza e se humaniza, a saudade é o sentimento dessa humanização do ser, ou seja, da liberdade essencial» ${ }^{42}$.

Para Pascoaes y la Renascença, el saudosimo representa el culto del alma portuguesa como credo religioso y emoción poética, en virtud de su ascendencia étnica. La saudade es el resultado de la fusión de la sangre semita y romana, de cristianismo y paganismo, es inagotable fuente de belleza divina, de arte y alma puramente lusitana (cfr: Teixera de Pascoaes, 1912: 113-115) ${ }^{43}$.

La influencia de Pascoaes en Galicia, como comenta Elena A. Riauzova (2000: 141), tiene un gran peso en el ámbito gallego, en toda la Xeración Nós:

40.- ("Tierras de Castilla", "Meditación preliminar", "Arte de este mundo y del otro", OO. CC. I, 187, "Nuevo libro de Azorín").

41.- Pascoaes tenía de mano a António Carneiro, que se convirtió en pintor de los símbolos de la Renascença. En el tríptico A Vida representaba la esperanza, el amor y la saudade. También el retratista Leonardo Coimbra en su Criacionismo, explicaba que el deseo de la Renascença era el de crear un "ideal colectivo".

42,- En António Quadros (1983: 33) y 1967, 1986.

43.- "O saudosismo e a Renascença", en A Águia, S. II, n." 10, outubro. 


\title{
PAISAJES, GEOGRAFÍA LITERARIA E IDENTIDAD NACIONAL
}

\begin{abstract}
Alla fine del diciannovesimo secolo alcuni scrittori portoghesi esercitarono una forte influenza sulla cultura galiciana; in primo luogo Teixeira de Pascoais con la sua poesia piena di tensione ideali, di spiritualismo e di idee di rinnovamento nazionale ha impressionato $\mathrm{i}$ cuori dei poeti naturalisti come António Noriega (1869-1947), e Eça de Queirós, dalla cui opera gli scrittori galiziani hanno preso soprattutto le forme brevi della narrazione.
\end{abstract}

En una tesis muy reciente, Federico López Silvestre (2005) analiza de una manera exhaustiva el discurso del paisaje en Galicia, centrando una parte de su trabajo, en concreto la cuarta, a la concepción estética del paisaje en la Xeración Nós ${ }^{44}$. Destaca, por ejemplo, cómo en Vicente Risco, tal y como expone en varios artículos de A Nosa Terra (1916-1936) y en su Teoría do nacionalismo galego, la etnicidad nacional de Galicia, suma de su lengua y de su cultura, es fruto asimismo del paisaje: «como el agua da a la piedra, gota a gota, su labranza, así el paisaje modela su raza de hombre, gota a gota» (1920: 25, 26 y 30). Risco, muy influido por cl determinismo geográfico, reúne los conceptos de tierra y etnia debajo del término alemán Volkgeist, que hace equivalente a nación:

A nacionalidade supón a terra. Porteiro creía con Renan e Jellinek qu’o que carauteriza á nación é unha unidade espiritual, mais, quen fai esta unidade espiritual? Eu insisto no valor da terra [...J Estes vínculos (fala, tradiciós, costumes, historia, etc.) añedindo a súa aución á da etnia y-a da terra, determinan nos individuos certas coincidencias psicolóxicas, certa maneira de sere común a todos eles, que constitue o carauter nacional (1920: 17).

Pero a la raza peculiar es necesario añadir, como dice Risco, un territorio autónomo. Así sucede con Galicia, el espacio más Europeo de la península, independiente del resto de España por su clima, flora y fauna. La galeguidade surge entonces de la mezcla entre la raza y el paisaje (Risco, 1920b), con unas características propias: el amor a la tierra, la saudade, o el lirismo (vid. Beramendi, 1999: 14). Por estos mismos años, Antón Vilar Ponte expone en la Doctrina nazonalista (1921) que la diferencia racial y geográfica constituyen la base indiscutible del concepto de nación, Antón Vilar Ponte mantiene en "Fontenla viva da nosa cultura" (1927) que «somentes é rexión, somentes é unidade xeográfica natural aquel anaco de planeta cuios caracteres típicos poden acharse presentes n'unha sola visión [y que esa] xeografía física ten que condicionar estreitamente a xeografía política» (citado en El discurso del paisaje: 2005: 547).

El paisaje tuvo, sobre todo, una gran importancia en Ramón Otero Pedrayo y en su búsqueda de las características esenciales de la identidad gallega, de la manifestación externa de Galicia y de la galeguidade. Para Pedrayo paisaje y raza son «dúas palabras que na Galiza sempre camiñan xuntas» (1988: 83-84). El paisaje, tal y como manifiesta en su "Sentimento da terra" (Discurso de ingreso en la Academia Galega), no es un fenómeno impermeable e indiferente, sino que puede ser ordenado por «individoalidás creadoras» (1931: 92), «pol-a raza, non a raza pol-a paisaxe, porque a outura e a beleza do probrema non consinte as saídas doadas dun determinismo calquera» (1931: 14).

La inclinación de Otero Pedrayo por el paisaje descansa, para C. Patterson (1998: 46), en su vinculación con el grupo del 98. Patterson revela que cl autor gallego recibió en Madrid casi la misma formación que se les diera a los de la Generación, diez o quince años antes, "cousa que explica, cando menos, moitas semellanzas entre Otero e maila Xeración do 98 na súa non distinta procura por medio da paisaxe de novas avaliacións da identidade nacional e de ímpeto frescos para a rexeneración social e política».

44.- Consúltese el artículo de Joaquim Ventura sobre la visión ideal de los gallegos en la obra de Castelao, Risco y Pedrayo (1999). Véase también el libro recientemente publicado por María López Sández A descrición topográfica: o seu papel na construción dun imaxinario cultural no discurso literario galego (Cantares gallegos, Arredor de si e o ciclo textual de Tagen Ata). Servizo de Publicacións e Intercambio Científico da Universidade de Santiago de Compostela: Santiago de Compostela. Edición en Cd-Rom que será publicado en papel en Paisaxe e nación: a creación discursiva do territorio. 


\section{Ma TERESA VILARIÑO PICOS}

Pero, a pesar de sus similitudes con los noventayochistas, Pedrayo se diferencia de ellos en su concepción de la raza como definitoria del paisaje, y no el paisaje como cualificador determinista de la raza: Galicia es «terra de humanizada paisaxe» (1987: 197), poseedora de «tema unánime que se nutre sempre da esencia do espírito da terra e da raza» (1987: 209). Con las nociones básicas de la filosofía idealista (Fichte, Schelling y Hegel), Pedrayo articula su propia visión del paisaje gallego como producto de la identidad gallega; si la cultura es la visión del mundo de un pueblo o de una nación, el paisaje es, al mismo tiempo, cultura e identidad, por lo menos según las imposiciones psicológicas de la conciencia subjetiva gallega, que expresa por medio del paisaje la profunda afinidad con el mundo natural externo y como identidad cultural (vid. Patterson, 1998: 47). La tríada de Taine que los noventayochistas hicieron propia (paisaje-carácter-cultura), se transforma en Pedrayo en carácter-paisaje y cultura.

Todos estos autores mencionados en sus distintos marcos culturales se interrelacionaron de muchos modos, a partir de correspondencia, de traducciones, creando vínculos entre centro y periferia, "canonización y autonomía", creando «redes culturales que engendran un diálogo interliterario capaz de regular los intercambios para que el sistema funcione y no termine colapsado» (D. Romero, 1998: 65-66). El artículo de Juan Ribera Llopis y Olivia Rodríguez González (1999), titulado “A imaxe e o concepto de 'galego' nas literaturas galega, castelá e catalana da fin do século XIX" es una manifestación muy evidente de los intercambios entre autores y, sobre todo, de la imagen de Galicia desde Castilla y Cataluña. Entre estos intercambios hallamos, por ejemplo, el mantenido desde 1905 entre Miguel de Unamuno y Teixeira de Pascoaes, a raíz de su primer encuentro en Salamanca. Y precisamente uno de los momentos más importantes en la relación epistolar que mantuvieron los dos autores es el de la aparición de A Aguia, en 1911, como ya hemos mencionado. Pascoaes le escribe una carta a Unamuno, con fecha de 8 de diciembre de 1910, en donde le pide colaboración, además de hacerle socio honorario, para formar parte del comité de la revista. A Unamuno se le atribuye, en fin, desde Portugal, la capacidad de captar con gran sensibilidad «a nossa Paisagem e a nossa Alma, apesar do seu temperamento ser diferente do português» (Pascoaes, 1988: 24) $\mathrm{Y}$, a pesar del temperamento diferente, de su dispar naturaleza cualitativa, el español es un «mármore criado», el portugués una «névoa criadora», el español, un ser ya definido, el portugués, indefinido (ibidem), ambos coinciden en la fuerza del paisaje para convertirse en metáfora de la tristeza peninsular, de la individualidad de la raza y, por ello, de la identidad de cada pueblo.

\section{REFERENCIAS BIBLIOGRÁFICAS}

Abad, Francisco (1987). Literatura e historia de las mentalidades. Madrid: Cátedra.

- (1992). "La palabra y el concepto meseta". En Homenaje a don Ángel Cabo. Salamanca: Universidad, I, 35-42.

— (1996). "Función estética c ideología del paisaje en la literatura". En Darío Villanueva y Fernando Cabo Aseguinolaza, eds., Paisaje, juego y multilingüismo. Actas del X Simposio de la Sociedad Española de Literatura General y Comparada. Santiago de Compostela: Servicio de Publicacións da Universidade de Santiago de Compostela, vol. I, 105-115.

Abellán, José Luis (1973). Sociología del 98. Barcelona: Península.

- (1996). Historia del pensamiento español. Madrid: Espasa-Calpe.

Anderson, Benedict (1983). Imagined Communities. Reflections on the Origin and Spread of Nationalism. Londres: Verse

Ayala, Francisco (1996). "El paisaje y la invención de la realidad". En Darío Villanueva y Fernando Cabo Aseguinolaza, eds., Paisaje, juego y multilingüismo. Actas del X Simposio de 


\section{PAISAJES, GEOGRAFÍA LITERARIA E IDENTIDAD NACIONAL}

la Sociedad Española de Literatura General y Comparada. Santiago de Compostela: Servicio de Publicacións da Universidade de Santiago de Compostela, vol. I, 23-30.

Azcona, Jesús (1984). Etnia y nacionalismo vasco (una aproximación desde la antropología). Barcelona: Anthropos.

Azorín (1912), "La España de Gautier”. En OO. CC. Madrid: Aguilar, vol. I.

Baroja, Ricardo [1952] (1989). Gente del 98. Arte, cine y ametralladora. Edición de Pío Caro Baroja. Madrid: Cátedra.

Beramendi, Justo G. (1999). "Unha imaxe ambivalente e cambiante: os galegos segundo os galeguistas (1840-1950)". En Dicter Kremer, ed., A imaxe e o concepto de "galego" fóra e dentro de Galicia. V Congreso Internacional de Estudos Galegos. Universidade de Tréveris, 8-1I de outubro de 1997. Sada: Edicións do Castro, vol. I, pp. 3-21.

Cabo Aseguinolaza, Fernando (2001). "La novela picaresca y los modelos de la Historia literaria". En Edad de oro, XX.

Calvo Serraller, Francisco (1998). Paisajes de luz y muerte. La pintura española del 98. Barcelona: Tusquets.

Caro Baroja, Julio (1981). Paisajes y ciudades. Madrid: Taurus.

Carvalhão Buescu, Helena (1996). "Paisagem, literatura e descrição". En Darío Villanueva y Fernando Cabo Aseguinolaza, eds., Paisaje, juego y multilingiïismo. Actas del X Simposio de la Sociedad Española de Literatura General y Comparada. Santiago de Compostela: Servicio de Publicacións da Universidade de Santiago de Compostela, vol. I, 193-199.

Claudon, Francis (1996). "Le Paysage en littérature comparée”. En Darío Villanueva y Fernando Cabo Ascguinolaza, eds., Paisaje, juego y multilingüiismo. Actas del X Simposio de la Sociedad Española de Literatura General y Comparada. Santiago de Compostela: Scrvicio de Publicacións da Universidade de Santiago de Compostela, vol. I, 201-208.

Claval, P. (1992). "Champs et perspectives de la géographie culturelle". En Géographie et Cultures, vol. 1. 1, pp. 7-38.

— (1996). "Les points-clefs de la géographic culturelle". En Bulletin de l'Association de géographes français, 73 année, 1 (janvier), pp. 1-10.

Facundo, Tomás (2000). Las culturas periféricas y el síndrome del 98. Barcelona: Anthropos.

Fox, Inman (1988). “Azorín y la coherencia (Ideología, política y crítica literaria)”. En Ideología y política en las letras de fin de siglo. Madrid: Espasa-Calpc, pp. 121-156.

- (1997). La invención de España. Nacionalismo liberal e identidad nacional. Madrid: Cátedra.

Fusi Aizpurúa (1984). El país vasco. Pluralismo y nacionalidad. Madrid: Alianza.

Gómez. Mendoza, Josefina y Nicolás Ortega Cantero, dirs. (1992). Naturalismo y Geografía en España (Desde mediados del siglo XIX hasta la Guerra civil). Madrid: Fundación Banco Exterior.

Guillén, Claudio (1996). "El hombre invisible: paisaje y literatura en el siglo XIX". En Darío Villanueva y Fernando Cabo Aseguinolaza, eds., Paisaje, juego y multilingiiismo. Actas del X Simposio de la Sociedad Española de Literatura General y Comparada. Santiago de Compostela: Servicio de Publicacións da Universidade de Santiago de Compostela, vol. I, 67-83. 


\section{$M^{\mathrm{a}}$ TERESA VILARIÑO PICOS}

— (1998). Múltiples moradas. Ensayo de Literatura Comparada. Barcelona: Tusquets.

Haes, Carlos de (1860). "De la pintura de paisaje antigua y moderna". En Discursos leídos en las recepciones y actos públicos celebrados en la Real Academia de las tres nobles artes de San Fernando. Madrid, 1872, 291.

Izquierdo Ballester, Santiago (1993-1995). Bartomeu Robert $i$ Yarzábal (1842-1902). Medicina $i$ comprimís cívic. Universidad Pompeu Fabra. Tesis doctoral recogida en tdx.cesca.es/TESIS_ UPF/AVAILABLE/TDX-1120103-104926//tsibldel.pdf.

Lafuente Ferrari, Enrique (1972). La vida y el arte de Ignacio Zuloaga. Madrid: Revista de Occidente.

Lafuente Ferrari, Enrique (1990). "Zuloaga, la pintura como fuerza”. En Zuloaga. Los genios de la pintura española. Madrid: Sarpe.

López Sández, María (2007). A descrición topográfica: o seu papel na construción dun imaxinario cultural no discurso literario galego (Cantares gallegos, Arredor de si e o ciclo textual de Tagen Ata). Santiago de Compostela: Servizo de Publicacións e Intercambio Científico da Universidade de Santiago de Compostela.

López Silvestre, Federico (2005). El discurso del paisaje. Historia cultural de una idea estética en Galicia (1723-1931). Santiago de Compostela: Servicio de Publicacións da Universidade de Santiago de Compostela.

Lourenço, E. (1978). O Labirinto da Saudade, Lisboa.

Lozano Marco, Miguel Ángel (2000). Imágenes del pesimismo. Literatura y arte en España 1898 1930. Alicante: Publicaciones de la Universidad de Alicante.

Mainer, José-Carlos (1982). Regionalismo, burguesía y cultura: Revista de Aragón (1900-1905) y Hermes (1917-1922). Zaragoza: Guara editorial.

Maravall, J. A. (1984). Estudios de historia del pensamiento español. Madrid: Cultura Hispánica, vol. II.

Martínez de Pisón, Eduardo (1998). Imagen del paisaje. La Generación del 98 y Ortega y Gasset. Madrid: Caja Madrid, 1998.

— (2002). "Reflexiones sobre el paisaje". En Ortega Cantero, Nicolás, ed., Estudios sobre historia del paisaje español. Madrid: Servicio de Publicaciones de la Universidad Autónoma de Madrid, 13-24.

—, y Concepción Sanz Herráiz, eds. (2000), Estudios sobre el paisaje. Madrid: Universidad Autónoma de Madrid y Fundación Duques de Soria.

Morales Moya, Antonio (2002). "Notas para una geografía cultural de la Ilustración española". En Ortega Cantero, Nicolás, ed., Estudios sobre historia del paisaje español. Madrid: Servicio de Publicaciones de la Universidad Autónoma de Madrid, 43-55.

Motta Oliveira, Paulo Fernando (1990). "Pascoaes: Da Saudade como Releitura de Portugal". En Revista Epa, n." 15, 1." sem. Campinas.

Mourelle de Lema, Manuel (1999). El 98 hispánico con atención especial a Galicia. Madrid: Grugalma Ediciones.

Ortega Cantero, Nicolás, ed. (2002). Estudios sobre historia del paisaje español. Madrid: Servicio de Publicaciones de la Universidad Autónoma de Madrid. 


\section{PAISAJES, GEOGRAFÍA LITERARIA E IDENTIDAD NACIONAL}

— (2004). Naturaleza y cultura del paisaje. Madrid: Ediciones de la Universidad Autónoma de Madrid.

Ortega y Gasset, José (1906). "La pedagogía del paisaje”. En El Imparcial, 17 de septiembre. Se cita por OO. CC., Madrid: Alianza Editorial-Revista de Occidente, tomo I, p. 55.

— (1910). “ ¿Una exposición Zuloaga?”. En El Imparcial, 29 de abril. Se cita por OO. CC., tomo I.

— (1910). "Viaje de España”. En El Imparcial, junio. Se cita por OO. CC., tomo I.

— (1915). "De Madrid a Asturias o los dos paisajes". En El Espectador, vol. III. (OO. CC., tomo II, 247).

- (1916). Personas, obras, cosas. Se cita por OO. CC.

- (1916). "Tierras de Castilla. Notas de andar y ver". En La vida entorno de El Espectador I. Se cita por OO. CC., tomo II , pp. 43.46.

— (1917). "El casticismo y lo castizo". En El Espectador II. Se cita por OO. CC.

— (1921). "Notas de andar y ver". En El Espectador III. Se cita por OO. CC.

Otero Pedrayo, R. (1931). Romantismo, saudade, sentimento da raza e da terra en Pastor Díaz, Rosalía de Castro e Eduardo Pondal (Discurso de Ingreso na Academia Galega coa contesta do académico Vicente Risco). Santiago: Nós.

— (1932). Morte e resurreición. Ourense: Aláuda.

— (1987). Ensaio histórico sobre a cultura galega. Vigo: Galaxia.

— (1988). "Un poema de A. Zapata García". En Prosa miúda. Artigos non coleccionados (19271934). Sada: Edicións do Castro. Publicado originalmente en El Pueblo gallego, 11 de octubre de 1930.

Pascoaes, Teixeira (1978). Arte de Ser Portugês. 3." ed. Lisboa: Ed. Delraux.

- (1988a). A Saudade e o Saudosismo. Lisboa: Editora Assíro \& Alvim. Org. Pinharanda Gomes.

— (1988b). A Saudade e o Saudosismo (dispersos e opúsculos). Cooperativa editora e livreira.

Patterson, Craig (1998), "Paisaxc, Filosofía e identidade. Resposta galega ó legado do 98". En $A$ Trabe de ouro, ano 9, n. 35 (Xulio-setembro), pp. 331-340.

Pena, María del Carmen (1982). Pintura de paisaje e ideología. La generación del 98. Madrid: Taurus.

Piveteau, J. L. (1994). Le territoire est-il un lieu de mémoire? Friburgo.

Quadros, António (1967). O Espírito da Cultura Portuguesa. Lisboa: Sociedade de Expansão Cultural.

— (1983). Poesia e Filosofia do Mito Sebastianista. Lisboa: Guimarães \& C. Editores, vol. II.

— (1986). "A Idéia de Portugal na Literatura Contemporânea (5)- Por uma Renascença Portuguesa”. En Tempo, 14 de octubre.

Renan, E. (1882). "Quést-ce qu'une nation?" En OO. CC., III. Madrid: Afrodisio Aguado, 1958, pp.173-174.

Riauzova, Elena A. (2000). "La letteratura portoghese e la lusofonia. Come superare il complesso 


\section{Ma TERESA VILARIÑO PICOS}

della 'piccola' nazione mediante il centrismo interlleterario". En Dionýz Durišin y Armando Gnisci. Il Mediterráneo. Una rete interletteraria. Roma: Bulzoni Editore, 137-149.

Ribera i Rovira (1911). Portugal y Galicia, nación.

Ribera Llopis, Juan y Olivia Rodríguez González (1999). “A imaxe e o concepto de 'galego' nas literaturas galega, castelá e catalana da fin do século XIX”. En Dieter Kremer, ed., A imaxe e o concepto de "galego" fóra e dentro de Galicia. V Congreso Internacional de Estudos Galegos. Universidade de Tréveris, 8-11 de outubro de 1997. Sada: Edicións do Castro, vol. I, pp. 73-83.

Risco, Vicente (1920a). Teoría do nacionalismo galego. Ourense: La Región.

— (1920b). "O sentimento da terra na raza galega". En Nós, n. ${ }^{\circ} 1,30-\mathrm{X}, \mathrm{pp} .4-9$.

Rocha, Clara (1985). Revistas Literárias do Século XX em Portugal. Imprensa Nacional da Casa da Moeda.

Romero López, Dolores (1998). Una relectura del "fin de siglo" en el marco de la Literatura Comparada: Teoría y praxis. Berna: Peter Lang.

Sauer, Carl O. (1971). Introducción a la geografía histórica. Resistencia Chaco: Instituto de Geografía, Facultad de Humanidades.

Samuel, Paulo (1990). A Renascença portuguesa. Um perfil documental. Porto: Fundaçao Eng. António de Almeida.

Valdés, Mario J. (1998). "The Hermeneutics of Comparative Literary History". En Poetica, 50, 79-96.

- (1999). "Culturas literarias latinoamericanas: una historia comparada". En Ibero-Americana Pragensia, Año XXXIII, 211-217.

— y Linda Hutcheon (1994). Rethinking Literary History Comparatively. American Council of Learned Societies. ACLS, 27

Varela, Javier (1999). La novela de España. Los intelectuales y el problema español. Madrid: Taurus.

Ventura, Joaquim (1999). “A visión ideal dos galegos para os homes do “Grupo Nós”" En Dieter Kremer, ed., A imaxe e o concepto de "galego" fóra e dentro de Galicia. V Congreso Internacional de Estudos Galegos. Universidade de Tréveris, 8-11 de outubro de 1997. Sada: Edicións do Castro, vol. 1, pp. 61-73.

Villar Ponte, Antón (1921). Doctrina nazonalista. Ferrol.

— (1927). "Fotenla viva da nosa cultura". En Nós. Ourense. 15 de febreiro, n. ${ }^{\circ} 38$, ano IX, pp. 2-8. 